\title{
Accessing City-County Data Book via DBASE III: \\ Census CD-ROMs from the Ground Up
}

\author{
Fred Gey \\ Data Archivist
}

UC Data Archive \& Technical Assistance (UC DATA)

(formerly State Data Program)

University of California

Berkeley, CA 94720

Presented to the 1990 Conference of the International Association of Social Science

Information Service and Technology (IASSIST90), Poughkeepsie, New York, May 30 to June $2,1990$.

The Bureau of the Census has published the 1988 City-County Data Book data files on a CD-ROM disk. Physically the data are organized as DBASE-III database files and the Bureau has supplied a computer program to display profiles of particular areas. However, accessing the data for analysis purposes (such as finding the ethnicity of American counties) can only be done by directly using DBASE-II, and doing so is a multi-step process. This paper describes how to use DBASE-III directly on CCDB88 to select subsets of data for statistical analysis, and compares and constrasts the CCDB88 structure with the 1982 Census of Agriculture files on Test Disk 2. Some suggestions are made for how the Bureau might organize CD-ROM data and access software to better facilitate individual access and prepare for the 1990 Census. 


\section{Accessing City-County Data Book with DBASE III}

\section{Introduction}

In the 1990s the Bureau of the Census will utilize the CD-ROM as a major publishing medium for current and future census data. This process has been underway for several years and the Bureau has been through several iterations of test disks before settling on a de-facto standard for distribution file formats of the DBASE-III database system by Ashton-Tate Corporation. While some measure of standardization is imposed by this decision by the Bureau, other standards and capabilities need to be added for the convenience of public data users of census data. It is the purpose of this paper to discuss the kinds of tasks which might be commonplace by data users and the effort required to accomplish them, as well as to draw some conclusions as to the structure the Bureau might impose to ease the burden of accessing this data.

\section{What is CD-ROM?}

$\mathrm{CD}-\mathrm{ROM}$ is a new data storage medium based on audio compact disk technology. Each cdrom disk holds about 650 megabytes of data (about the equivalent of 4 computer magnetic tapes as we know them on the IBM mainframe). Since the production process is identical to that of compact disks, the cost of production is about the same (less than $\$ 5$ per disk).

CD-ROM can be conceived of as an extremely large and slow disk that you can't write on. It operates like a cross between a hard disk (because it's so big) and a floppy (because the disks are removable). On the IBM-AT machine in our archive, we have attached a CD-ROM drive from Denon Corp, and designated it to be drive F:

Thus if we have the City-County Data Book disk inserted in the drive we can do a directory command to see what files are on the drive:

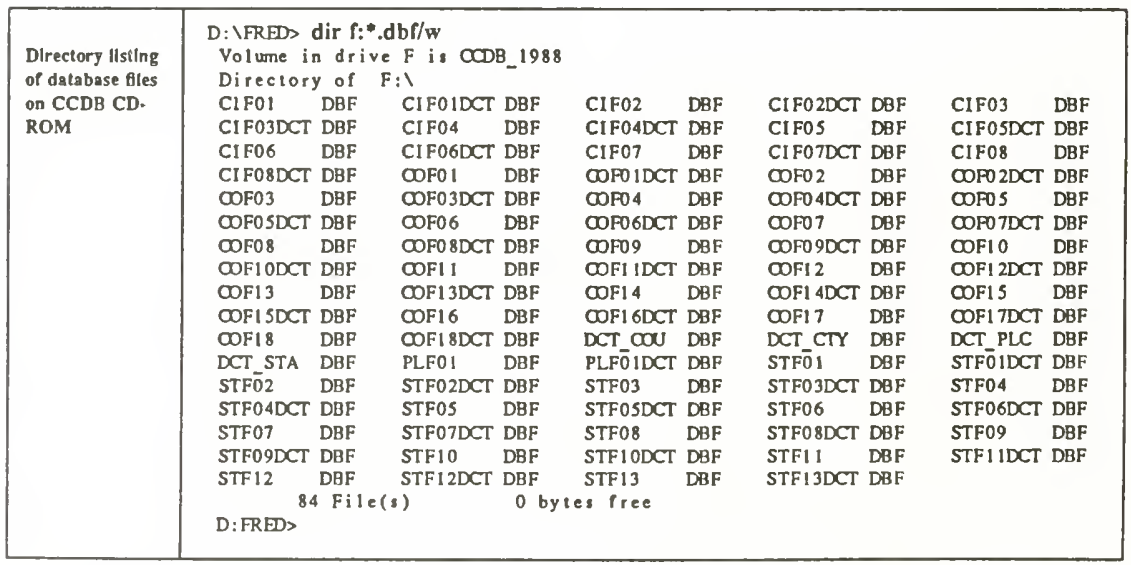


3. What data is available?

We currently have data from the Census Bureau, and will soon obtain a great deal more. The following data files are on hand:

\begin{tabular}{|c|l|l|}
\hline Disk & File & Geography \\
\hline TEST1 & 1980 Census, STF3 & zipcode \\
AHS85 & 1985 American Housing Survey, National Core & nat/state \\
TEST2 & $\begin{array}{l}\text { 1982 Census of Agriculture } \\
\text { 1982 Census of Retail Trade } \\
\text { zipcode } \\
\text { CCDB }\end{array}$ & $\begin{array}{l}\text { state/county/ } \\
\text { city/place }\end{array}$ \\
\hline
\end{tabular}

TABLE 1 : CD-ROM Databases at UC DATA

\section{Accessing CD-ROM data: City-County Data Book}

The Census Bureau has supplied some access software (in the form of canned profiles which can be applied to generate reports for particular areas), all of which is located in the CDROM subdirectory on drive $C$ in the archive. One of these is the CCDB profile program, which can be accessed as follows:

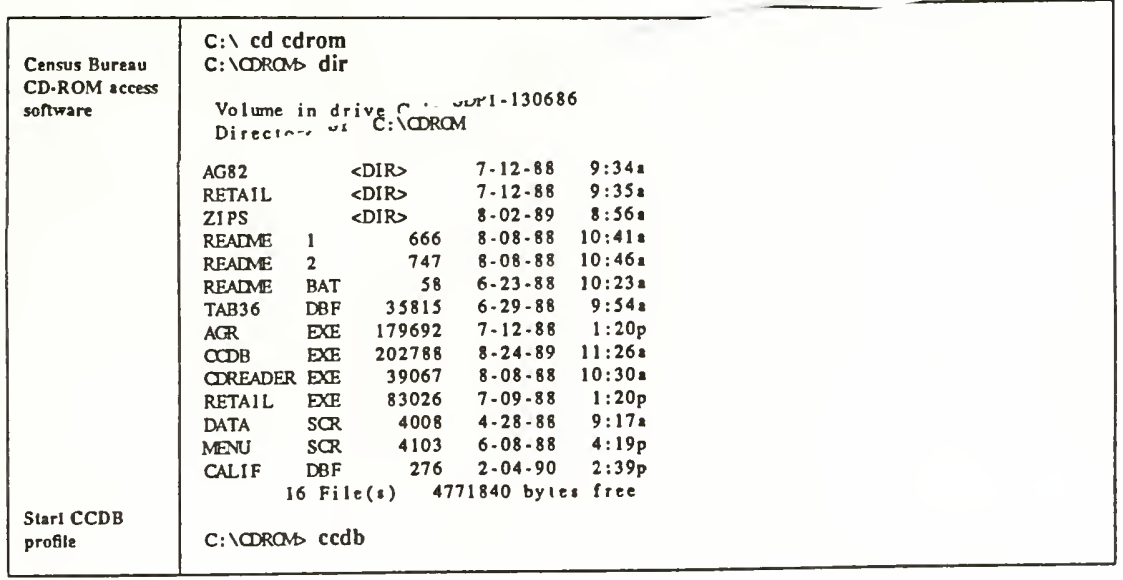




\begin{tabular}{|c|c|}
\hline \multirow{3}{*}{ Callornia } & I STATES I Cities of 25.000 or more \\
\hline & I AL AK AZ AR CA $\infty$ CT DE DC FL I AZU : \\
\hline & I GA HI ID IL IN IA KS KY LA ME (Bjkersfold W \\
\hline \multirow[t]{5}{*}{ then Bakersfield } & I MD MA MI MN MS MD MT NE NV NH I Baldwin Park \\
\hline & I NJ MM NY NC ND OH OK OR PA RI I Bell \\
\hline & I SC SD TN TX UT VT VA WA WW WI I Bellfower \\
\hline & I WY CALIFORNIA \\
\hline & l="==" \\
\hline \multirow[t]{12}{*}{ then Land Area } & $\begin{array}{l}\text { SUBJECTS } \\
\text { LAnd AS O ard Populafion }\end{array}$ \\
\hline & I Vital Statistics and Health \\
\hline & $\begin{array}{l}\text { I Social Welfare Programs (" not covered in this geographic area) } \\
\text { I Crime and Education }\end{array}$ \\
\hline & I Money lneome and Poverty Status \\
\hline & $\begin{array}{l}\text { I Personal Income (* not covered in this geographic area) } \\
\text { Housing }\end{array}$ \\
\hline & I Civilian Lebor Force and Employment \\
\hline & I Agriculture (" not covered in this geographic area) \\
\hline & I Manufactures \\
\hline & I Construction (" not covered in this geogrsphic area) \\
\hline & I Wholesale and Retait Trade \\
\hline & 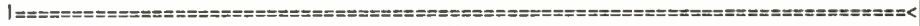 \\
\hline & -Cursor < Enter-Seleet PgUp-Page Up PgDn-Page Down Esc-Reset \\
\hline
\end{tabular}

Choosing the city of Bakersfield and the Land Area and Population subject (as shown by shading above) will give the following data about Bakersfield:

Data display for clty of Bakersfield, CA

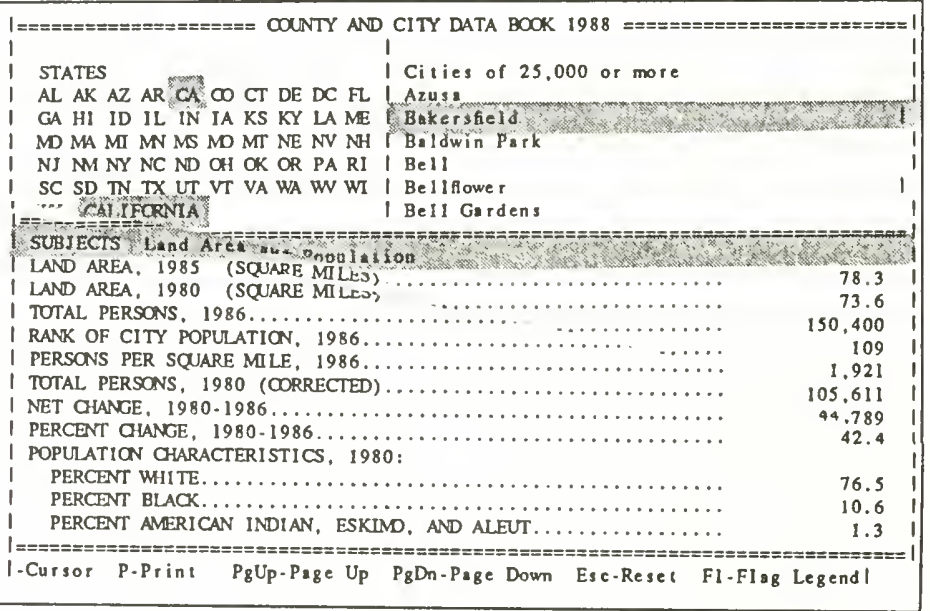

City county data book has data for four levels of geography: states, counties within states, cities (of 25,000 population or greater), and census designated places (including unincorporated towns of 2,500 population or greater for which census data has been tabulated). The example above retrieved the first screen of items available for the city level of geography. 


\section{1. $\mathrm{CCDB}$ individual data}

As part of the UC DATA operations and services on CCDB, the following tasks might be desired:

- Obtain a data file of all cities and towns in Califomia containing population and percapita income.

- Determine which counties in the United States have Hispanic population greater than 15 percent of total population, and rank them by percent Hispanic.

In order to achieve these tasks we must use DBASE-III directly. Assuming we have started DBASE correctly, and then set the drive to $F$, and the following screen should appear:

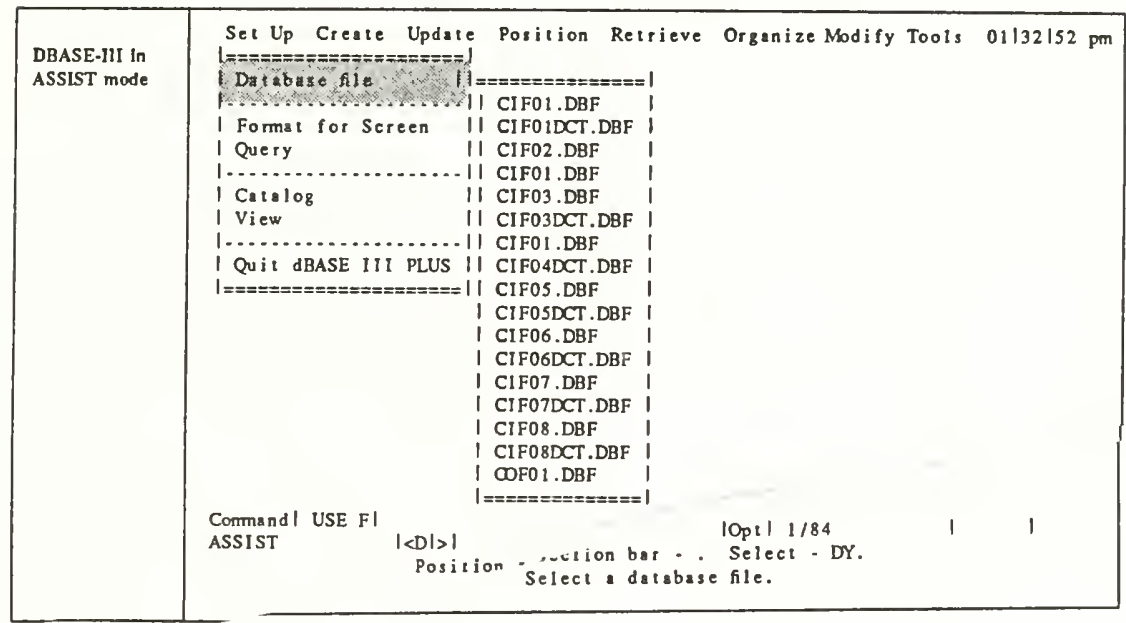

\subsection{Choosing California Towns and Cities}

In order to obtain data for towns and cities in California, we need to know (from the Census Bureau Documentation [CENSUS 89]) that the data file we are looking for is the Place file which contains incorporated and unincorporated (census designated) places with 2,500 or greater population in 1980. We must choose this file as our DBASE data file. This is easiest done by pressing the ESC key until we get the DBASE command prompt (the dot in column 1) and typing the "use <data base file>" command, and then using the DBASE copy command to actually create the new file. 


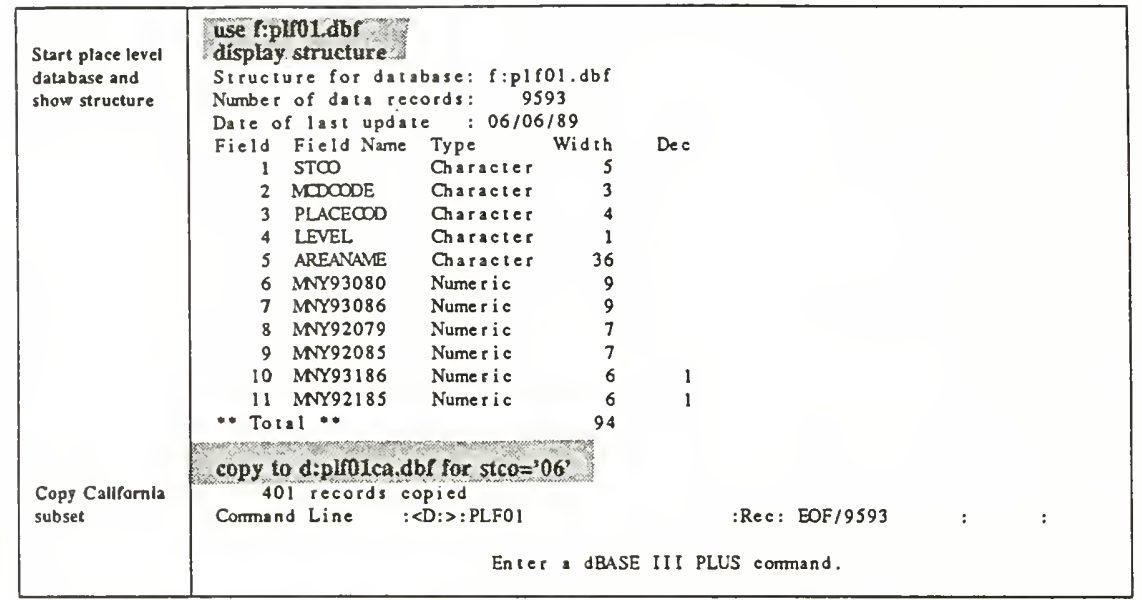

and then we can browse the new file to see its contents.

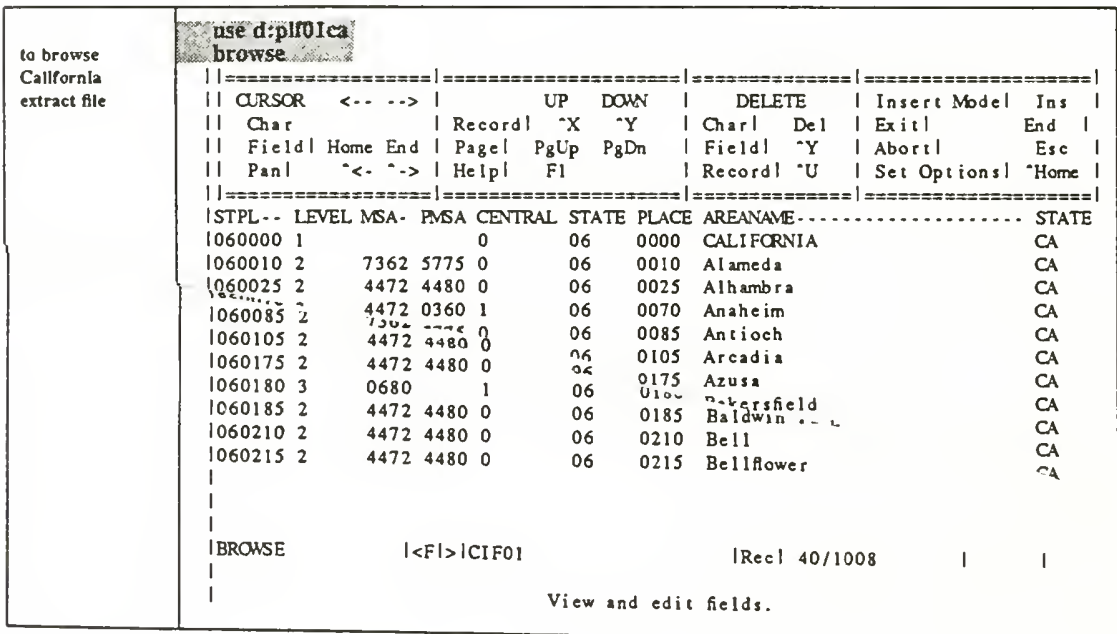

\subsection{Selecting Hispanic Counties}

While obtaining California places only presented a mild challenge, the process of discovering US counties with substantial Hispanic population concentration requires significantly more detective work. The Census Bureau does not make it easy because they don't include a comprehensive codebook to document the CCDB CD-ROM file, and so we must search for the data element (field in DBASE terminology) which has Hispanic population. We can begin by examining what documentation the Bureau does provide, as shown in the following table: 
Table 8. Counties - Population Chiaracteristics and Households

\begin{tabular}{|c|c|c|c|c|c|c|c|c|c|c|c|c|c|c|c|c|c|c|}
\hline \multirow{5}{*}{ County } & \multicolumn{12}{|c|}{ Populavon chersciensso-Con } & \multicolumn{6}{|c|}{ Mowomolds } \\
\hline & \multicolumn{9}{|c|}{$1834-C D n$} & \multicolumn{3}{|c|}{1880} & \multicolumn{3}{|c|}{ 10as } & \multicolumn{3}{|c|}{1980} \\
\hline & \multicolumn{9}{|c|}{ Percont - } & \multicolumn{3}{|c|}{ Porcent- } & \multirow[b]{2}{*}{ Number } & \multirow[b]{2}{*}{$\begin{array}{c}\text { Percemt } \\
\text { ensenos } \\
1980 \\
1985\end{array}$} & \multirow[b]{2}{*}{$\begin{array}{r}\text { Persons } \\
\text { per } \\
\text { nouse } \\
\text { noid }\end{array}$} & \multirow[b]{2}{*}{ Number } & \multicolumn{2}{|c|}{ Pweent - } \\
\hline & $\begin{array}{r}\text { Undor } \\
5 \\
\text { yours }\end{array}$ & $\begin{array}{r}5 \\
10 \\
14 \\
\text { yoes }\end{array}$ & $\begin{array}{r}15 \\
10 \\
24 \\
y 00 \\
\end{array}$ & $\begin{array}{r}25 \\
10 \\
34 \\
\text { rears }\end{array}$ & $\begin{array}{r}35 \\
6 \\
4 \\
\text { years }\end{array}$ & $\begin{array}{r}45 \\
60 \\
54 \\
\text { rears } \\
\end{array}$ & $\begin{array}{r}55 \\
6 \\
64 \\
y \\
\end{array}$ & $\begin{array}{r}65 \\
50 \\
74 \\
y e a r s \\
\end{array}$ & $\begin{array}{r}75 \\
\text { rears } \\
\text { and } \\
\text { over }\end{array}$ & $\begin{array}{c}\text { Amen } \\
\text { esen } \\
\text { Incien } \\
\text { Estumo. } \\
\text { sind } \\
\text { Nent }\end{array}$ & $\begin{array}{r}\text { Asuen } \\
\text { and } \\
\text { Peache } \\
\text { Stander }\end{array}$ & $\begin{array}{r}\text { Hiso- } \\
\text { pance' }\end{array}$ & & & & & $\begin{array}{c}\text { Fomala } \\
\text { ternily } \\
\text { nouse } \\
\text { nowoer }\end{array}$ & person \\
\hline & 14 & 15 & 18 & 17 & 101 & 10 & 201 & 21. & 22 & 201 & 24 & 25 & 28 & 27 & 28) & 29 & 50 & 31 \\
\hline & & & & 1 & & & & & & & & & & & & & & \\
\hline
\end{tabular}

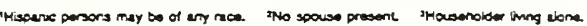

TABLE 2 : CCDB County Data Elements

the numbers above the column definitions refer to a field called ITEM<numbers in DBASE, where <number is replaced by the actual column number. Looking at the table, we find that percent Hispanic population is ITEM25. Unfortunately, however, we don't know which of the $18 \mathrm{DBF}$ files that ITEM25 is to be found. We can guess that it's probably in COF02.DBF, and display structure for this data subset, as shown below:

\begin{tabular}{|c|c|c|c|c|c|c|c|}
\hline 更 & $\begin{array}{l}\text { use fecof02.dhe } \\
\text { display structire } \\
\text { Strueture for data } \\
\text { Number of data rec } \\
\text { Date of last updat } \\
\text { Field Field Name } \\
1 \text { STCO } \\
2 \text { LEVEL } \\
3 \text { MSA } \\
4 \text { PMSA } \\
5 \text { AREANAVE } \\
6 \text { FLAG14 } \\
7 \text { ITEM14 } \\
8 \text { FLAG15 } \\
9 \text { ITEM15 } \\
10 \text { FLAG16 } \\
11 \text { ITEM16 } \\
12 \text { FLAG17 } \\
13 \text { ITEM17 } \\
14 \text { FLAG18 } \\
15 \text { ITEM18 } \\
16 \text { FLAG19 } \\
\text { Press any key to } \\
\text { Cormand Line }\end{array}$ & $\begin{array}{l}\text { abase: } f: c o f d \\
\text { cords: } 319 \\
\text { te : } 06 / 16 \\
\text { Type } \\
\text { Character } \\
\text { Character } \\
\text { Character } \\
\text { Character } \\
\text { Character } \\
\text { Numeric } \\
\text { Numeric } \\
\text { Numeric } \\
\text { Numeric } \\
\text { Numeric } \\
\text { Numeric } \\
\text { Numeric } \\
\text { Numeric } \\
\text { Numeric } \\
\text { Numeric } \\
\text { Numeric } \\
\text { continue... } \\
\text { D: }>\text { : } 0 \text { OFO2 } \\
\text { Enter }\end{array}$ & $\begin{array}{l}02 . d b f \\
91 \\
189 \\
\text { Wid ith } \\
5 \\
1 \\
4 \\
4 \\
36 \\
1 \\
6 \\
1 \\
6 \\
1 \\
6 \\
1 \\
6 \\
1 \\
6 \\
1 \\
\\
\\
\text { dBA }\end{array}$ & $\begin{array}{r}1 \\
1 \\
1 \\
1 \\
\text { III }\end{array}$ & $\begin{array}{l}\text { Reet 1/3191 } \\
\text { US cormand. }\end{array}$ & : & : \\
\hline
\end{tabular}

But as we can see, this isn't the case. 
Fortunately, the Census Bureau has not left us completely in the lurch. Several dictionary files have been constructed which describe the contents of the data items and where they are located in the many DBF files.

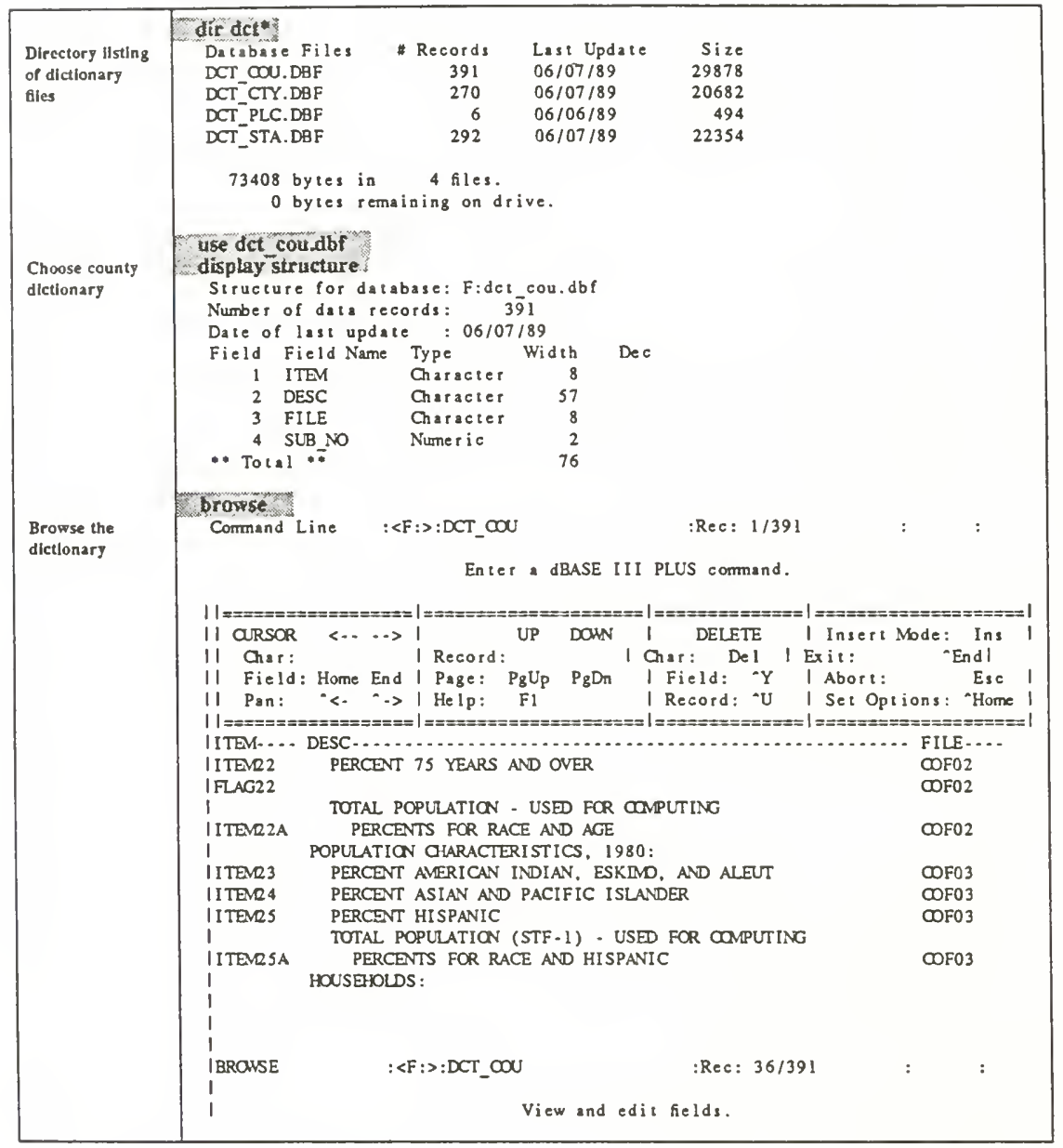

Using this dictionary file tells us what data base file to use (COF03.DBF) and which item (ITEM25) to use to search on and create our restricted file. 
We can now begin the process of determining which counties had high concentrations of Hispanics according the the 1980 Census.

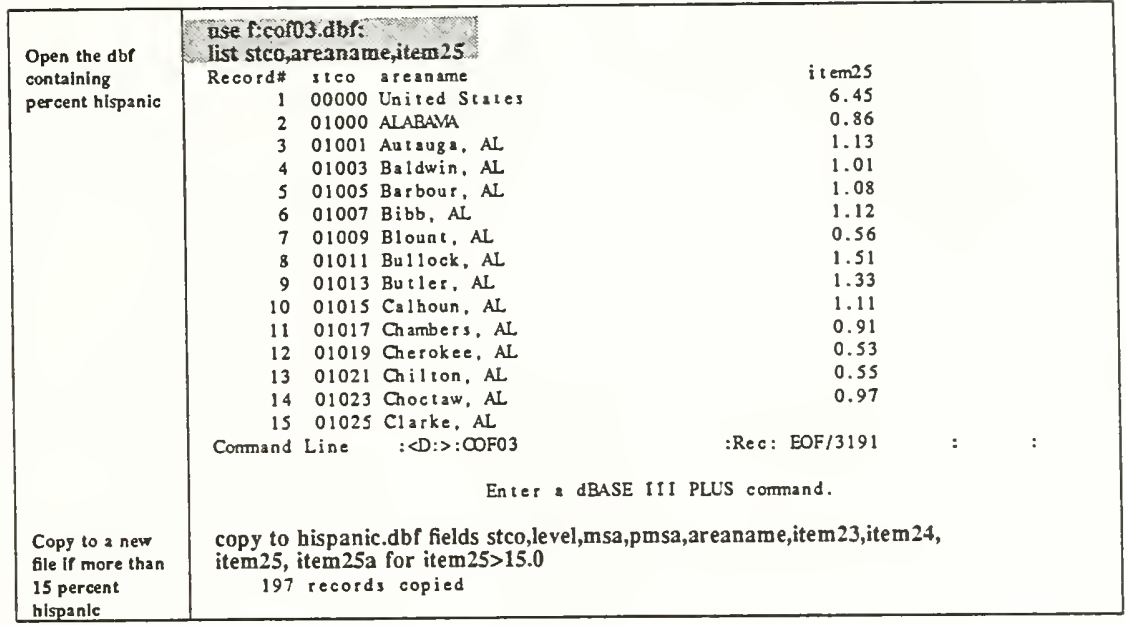

Once we have obtained this data file we must sort in descending order using the DBASE sort command, and then we can list the contents to find the highest Hispanic concentrated counties in the United States.

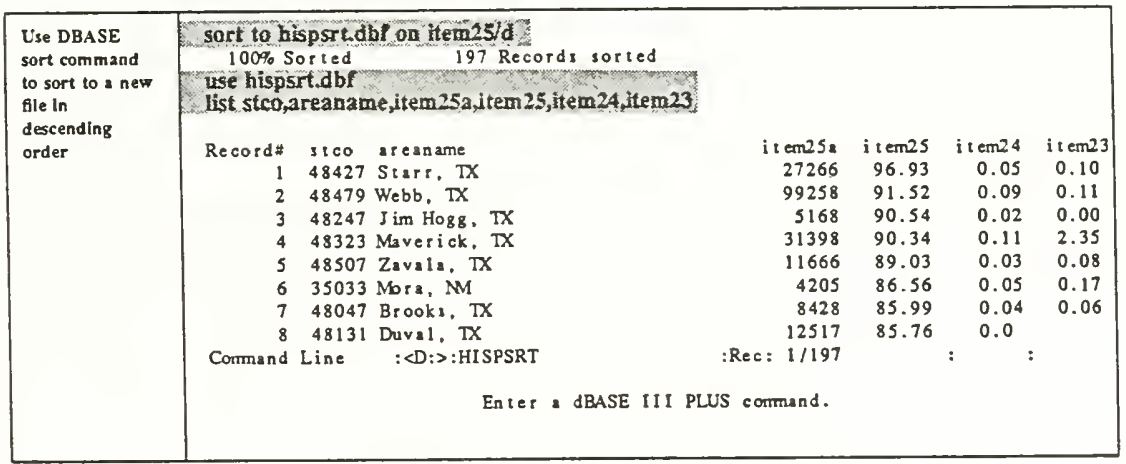

\section{1982 Census of Agriculture}

A task which one might wish to undertake is to draw information from the 1982 Census of Agriculture for counties with high Hispanic concentrations and combine it with the County data book information just obtained. Some of this information can be found in CCDB itself, but more detailed information would lead us to Census Bureau's CD-ROM TEST DISK 2 which contains the entire 1982 Census of Agriculure. If we pop this disk into our CD-ROM 
drive, we can see how the files are organized.

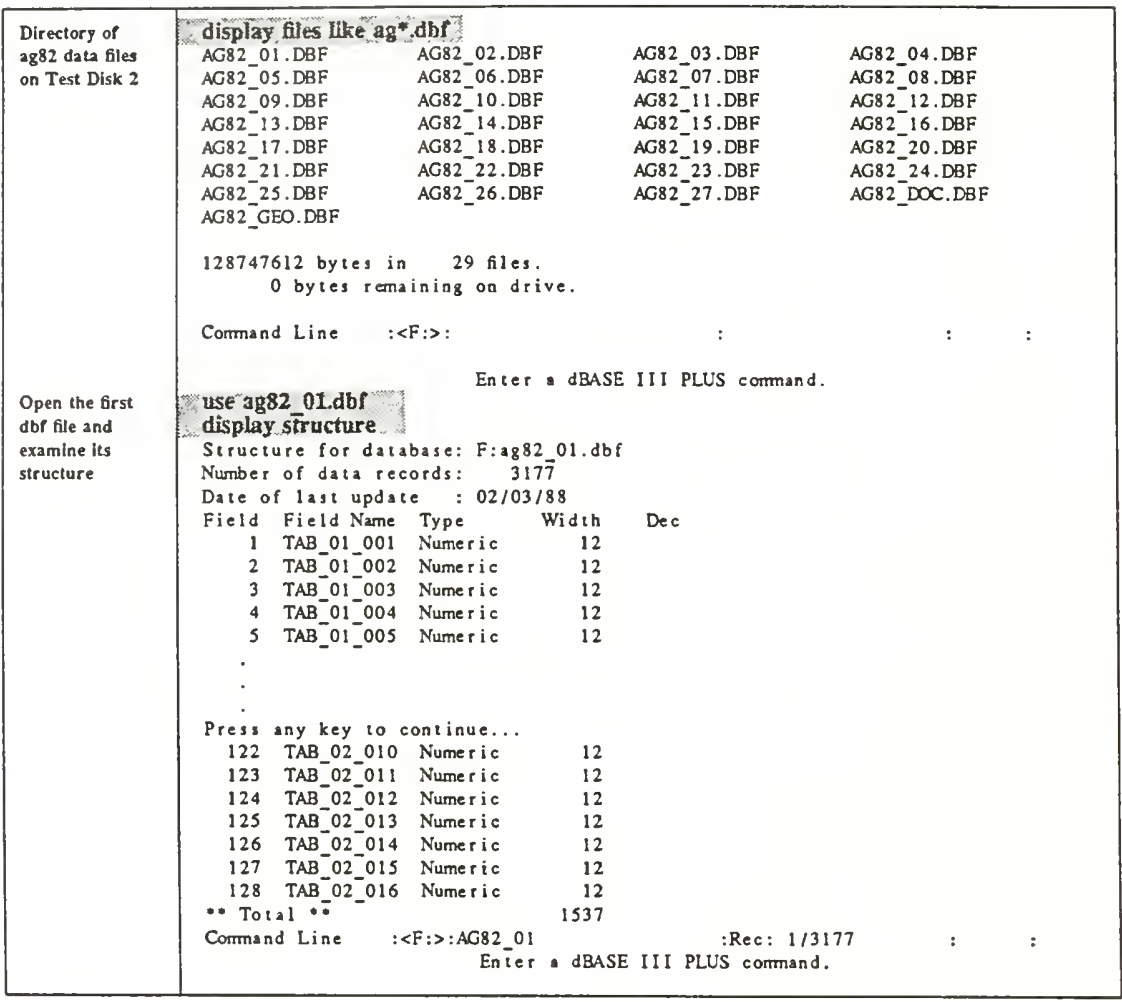

What we find is that the Agriculture data files, unlike the CCDB data files, don't have any geographic codes in their records! The sole place for the geographic codes is in a separate file AG82_GEO.DBF. What this means to the unwary analyst is that the DBASE command JOIN can't be used to merge files from these two databases; a substantially more complex program will have to be constructed if we wish to put together data from these two sources, even though they are ostensibly collected for the same counties. We can look at this geographic file and find out what it contains. 


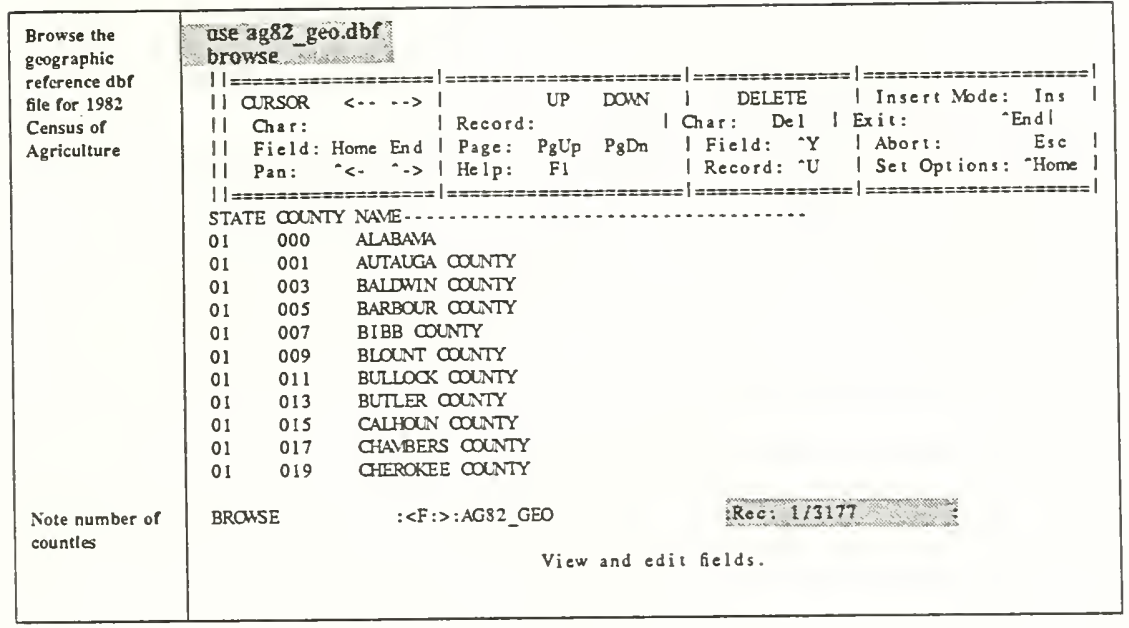

Notice that the geographic codes don't have the same name for the two databases. State and county codes are separate on the 1982 Agriculture geography file, while they are concatenated into a single STCO code in the $\mathrm{CCDB}$ database files. This further complicates the task of merging the two files. Finally, the above screen shows 3177 counties in the data file, while looking at the CCDB screen at the bottom of page 6 shows 3191 counties in the CCDB file. While this difference can be explained by the independent cities in Virginia and by the Bureau's not releasing Agricultural data for counties with fewer than ten farms, these facts further complicate the database compatibility problem.

Thus our preliminary investigation shows merging City-County Data Book with 1982 Census of Agriculture to be a complicated process beyond the scope of this paper. The key to making this process easier will be the development of standards for geographic coding.

\section{Conclusions and Recommendations}

While the Census Bureau has gone a long way toward making census data available on inexpensive personal computers, certain additional features will make accessibility of $\mathrm{CD}$ ROM census data to the average planner or statistician using these data.

The Census Bureau, in constructing CD-ROM products, should provide

- A comprehensive codebook for data dictionaries which not only names and describes each data item, but also gives its universe, so items are not inadvertantly combined.

a) An effort should be made to combine items having the same universe into the same DBASE file. 
- Uniformity of file structure across databases:

a) one record per geographic area

b) The same geographic units over all databases (e.g. either one file for all counties in the U.S. or one file per state)

c) The same geographic naming structure within each file and across databases

(e.g. STCO as in City-County Data Book or STATE, COUNTY as in 1982 Census of Agriculture). This is so that the DBASE 'JOIN' command can be used to connect data from different files or the 'LOCATE FOR' commands will use the same selection sequence for files being connected.

This purpose of this paper has been to give a glimpse of the effort necessary to do more than trivial tasks in retrieving data from the City-County Data Book on CD-ROM. In doing so we have uncovered some of the issues in access to census data. The availability of 1990 Census data on $\mathrm{CD}-\mathrm{ROM}$ will surely force social science information specialists to confront these issues in this new medium. The application of standards will resolve some problems, but others can be relieved with additional machine-readable documentation from the Census Bureau. 
The Merit Networking $\mathrm{S}$ e min a r s

MAKING YOUR NSF NET CON NECTION COUNT

Merit/NSFNET Information Services is committed to providing current information on national networking to all users of the NSFNET backbone. Toward this end we will sponsor a two-day seminar in Ann Arbor, Michigan. May 20 and 21. "Making Your NSFNET Connection Count" will be an informative seminar focusing on issues of interest to campus computing leaders, information systems and networking administrators, educational liaisons, librarians, and educators who want to learn more about national networking.

Day 1. "Real People Doing Real Things," will feature a numberof presentations concerning network applications in education from the elementary grades through the college level. The Day 1 activities will begin with a keynote address by Paul Evans Peters, Director, Coalition for Networked Information and will close with a tour of the Merit Network Operations Center.

Day 2. "How to Get Connected and Stay Connected" will provide local, state, midlevel, and national networking perspectives from the experts. Day 2 will also be comprised of presentations on internetworking. information/user services, and network operations.

The seminar will be held at the Tenneco Automotive Training and Development Center in Ann Arbor. Microcomputers connected to regional and national networks will be available on-site so that attendees may access network resources discussed in the presentations.

The registration fee is $\$ 395$. An early-bird fee of $\$ 345$ will be charged for registrations received before April 15, 1991. This fee includes the twoday seminar, a reception on Sunday evening. lunch on Monday and Tuesday, all seminar material, and an optional tour of the Network Operations Center.

For further information send an electronic message to seminar@merit.edu or telephone 1-800-66-MERIT.

\section{0 cartridges.}

For those interested in 3480 cartridges:

NTIS (PB8 233135) is selling for $\$ 12.95$ National Archives Technical Information Information Paper No. 4 "3480 Class Tape Certridge Drives and Archival Tape Storage: Technology Assessment Report."

Call 703/487-4600 or write to Document Sales NTIS, Springfield, VA 22161.

This paper covers the "mechanical \& technological future of the systems" \& "provides valuable information to data center managers data librarians, and archivists, in fact to all who are concerned about the long-term storage of machine-readable data." 